\title{
NILAI-NILAI DALAM RESOLUSI KONFLIK BERBASIS KEARIFAN LOKAL : Kajian Semboyan Patut Patuh Patju Kab. Lombok Barat NTB
}

\author{
LENNY HERLINA \\ Universitas Mataran \\ herlinalenny@gmail.com
}

\begin{abstract}
Abstrak
Pada dasarnya manusia tidak dapat menghindari perbedaan-perbedaan dengan manusia lainnya. Perbedaan tersebut dapat berupa perbedaan jenis kelamin, ekonomi, strata sosial, suku, agama, bahasa, sistem hukum, kepercayaan, budaya, ideologi, pilihan politik dan lain sebagainya. Dari perbedaan tersebut maka konflik adalah sebuah keniscayaan dalam percaturan sejarah umat manusia sehingga konflik merupakan esensi dari kehidupan dan perkembangan manusia. Meskipun konflik akan selalu ada bukan berarti tidak dapat diselesaikan, oleh sebab itulah resolusi konflik diperlukan untuk merekunstruksi dan merehabilitasi sistem sosial agar stabilitas sosial selalu terjaga dari generasi ke generasi. Adanya kearifan lokal yakni norma-norma yang telah lama terinternalisir di tengah-tengah masyarakat telah terbukti mampu mempertahankan harmoni sosial. Tulisan ini akan mendeskripsikan nilai-nilai resolusi konflik yang tersirat dalam semboyan pembangunan masyarakat Kabupaten Lombok Barat yaitu patut patuh patju yang telah disahkan oleh Peraturan Daerah Lombok Barat dengan Perda No.3 Tahun 1970. Semboyan tersebut meskipun dikenal luas sebagai semboyan pembangunan, namun sangat tepat dan menyentuh pula makna membangun resolusi konflik bagi masyarakat Lombok Barat yang memiliki beragam budaya yang saling mempengaruhi karena didiami oleh banyak masyarakat pendatang dan berbagai pemeluk agama.
\end{abstract}

Kata Kunci: Resolusi, Konflik, Kearifan Lokal, Patut Patuh Patju, Lombok Barat. 


\section{A. Pendahuluan}

Manusia adalah mahluk sosial yang untuk memenuhi kebutuhannya sendiri selalu melibatkan interaksi sesama manusia. Dalam kehidupan bermasyarakat, setiap individu tidak dapat terlepas dari perselisihan. Dampak ikutan dari suatu perselisihan mengakibatkan kerugian bagi pihak yang berselisih, baik antar individu dengan individu maupun kelompok dengan kelompok lainnya. Perselisihan individu maupun kelompok merupakan konflik yang terwariskan dalam kehidupan sosial. ${ }^{1}$ Konflik kemanusiaan yang terjadi di tengah-tengah komunitas masyarakat akhirakhir ini telah memotivasi berkembangnya dialog di tahan air secara intensif dan konstruktif. ${ }^{2}$

Konflik dimaknai sebagai hubungan antara dua pihak atau lebih yang memiliki tujuan atau kepentingan yang berbeda sehingga melatarbelakangi munculnya ketidakcocokan atau perbedaan pendapat dalam hal tujuan yang akan dicapai. ${ }^{3}$ Konflik merupakan salah satu karakteristik kehidupan manusia disegala zaman, di semua tempat, di semua sistem sosial, dan semua bidang kehidupan manusia. Bahkan Sejarah Indonesia dipenuhi dengan konflik. Baik pada masa kerajaan, masa kolonialisme sampai dengan masa kemerdekaan dan hingga kini, ${ }^{4}$ bahkan tentu saja hingga dunia ini berakhir kelak.

Konflik sebagai sesuatu yang tidak dapat dihindari biasanya dipandang sebagai sesuatu yang negative atau buruk. Padahal konflik adalah suatu yang manusiawi dan mempunyai fungsi positif selama dapat diterima dan diapresiasi dengan baik dan berpeluang mengasah kedewasaan dan keterampilan menyelesaikan masalah, baik secara personal maupun kelompok. Seseorang, sekelompok orang, bahkan bangsa dan negara menjadi maju jika mampu menerapkan manajemen konflik yang dihadapinya. ${ }^{5}$

\footnotetext{
${ }^{1}$ Newstrom, J. and Davis, K. Human Behavior at Work. Organization Behavior 8th Edition. Singapore: Mc. Graw-Hill. International 1993.

2 Fahrurrazi, "Konflik Agama dan Etika Dialog: Membaca Dialog Kemanusiaan dalam Bingkai Sosiologi Komunikasi," Jurnal Tasamuh 12, Nomor. 1 (Desember 2014).

${ }^{3}$ Pupun Sofiyati, dkk, Konflik dan stress; pengembangan dan perilaku organisasi. Malang: Universitas Brawijaya. 2011. h. 2.

${ }^{4}$ Wirawan. Konflik dan manajemen konflik. Jakarta: Salemba Humanika. 2010. h. vii

5 Prof. Dr. Gunaryo pada perkuliahan Pasca Sarjana S3 UIN Mataram mata kuliah Pendidikan Islam dan Resolusi Konflik. Hari Senin tanggal 28 Oktober via zoom.
} 
Demikian pula dengan masyarakat suku Sasak yang mendiami pulau Lombok, dengan keragaman bahasa, budaya, latar belakang etnis (para pendatang yang telah hidup berdampingan melebur bahkan memberi warna budaya yang khas) dan agama tentu memiliki ruang dan peluang untuk terjadinya konflik

Menurut Pace \& Faules konflik adalah ekspresi pertikaian antara individu dengan individu, kelompok dengan kelompok lainnya karena beberapa alasan. ${ }^{6}$ Dahrendrof menyebutkan bahwa konflik kepentingan biasanya dapat bersifat laten maupun bersifat manifest. Dikatakan konflik laten apabila konflik tersebut tidak disadari oleh individu atau kelompok, konflik disebut manifest apabila bentuk konflik dengan berbagai kepentingan tersebut terjadi melibatkan individu maupun kelompok. ${ }^{7}$ Dahrendrof melihat dua sisi dalam diri masyarakat yaitu konflik dan kerjasama. Dalam konteks sosial, tindakan-tindakan yang dilakukan oleh masing-masing individu ketika berinteraksi dengan sesama melahirkan fenomena yang secara umum kita sebut sebagai dialog. ${ }^{8}$

Lewis Coser beranggapan bahwa konflik selalu memiliki fungsifungsi positif jika dikelola dan diekspresikan sewajarnya. Baginya sistem sosial bersifat fungsional, sehingga konflik tidak selamanya bersifat negatif. Lewis Coser menyebutkan keberadaan konflik dapat memicu terciptanya dinamika masyarakat yangmemberi efek positif bagi soliditas grup. Bagi Lewis Coser terdapat tiga hal yang mendasari argumentasi. Pertama, situasi konflik akan meningkatkan kohesi internal dari kelompokkelompok terkait; kedua, mampu menciptakan assosiasi-assosiasi dan koalisi-koalisi baru dan ketiga, dengan konflik akan terbangun kesimbangan kekuatan antar kelompok terlibat. Menurut Lewis Coser konflik terbagi menjadi dua yaitu konflik realistis dan non-realistis. ${ }^{9}$

Setiap konflik baik laten maupun manifest, realistis maupun non realistis selalu membutuhkan resolusi konflik guna mengkonversi dari

${ }^{6}$ R. Wayne Pace dan Don F. Faules, Komunikasi Organisasi : Strategi Meningkatkan Kinerja Perusahaan, Editor Deddy Mulyana, Bandung: Remaja Rosda Karya, 2000, 185

7 Novri Susan, Sosiologi Konflik dan Isu-Isu Konflik Kontemporer, Jakarta: Kencana Prenada, 2009, h. 39. Lihat juga Novri Susan dalam buku Sosiologi Konflik: Teori-teori dan Analisis, Jakarta: Kencana Prenada, 2009, h 22

${ }^{8}$ Agus Dedi Putrawan, Sekolah Perjumpaan Sebagai Gerakan Dakwah Berbasis Komunitas, Jurnal Lentera, Volume 02, Nomor. 02, (2018), h. 215.

${ }^{9}$ Lewis Coser, the Function Of Social Conflict, New York, Routledge, 1956. 
konflik yang bersifat negatif menjadi konflik yang bersifat positif. Resolusi konflik pada umumnya berusaha yang memiliki tujuan untuk meyelesaikan konflik melalui pemecahan masalah secara konstruktif hingga tercapainya perdamaian. ${ }^{10}$

Resolusi konflik umumnya dapat dilakukan oleh pihak-pihak yang terlibat dalam konflik dan resolusi konflik diinisiasi oleh pihak ketiga. Penyelesaian konflik di luar konsultasi, negoisasi dan perdamaian, mediasi, konsiliasi dan arbitrase memerlukan penyelesaian melalui proses pradilan baik perdata maupun pidana. Penyelesaian konflik berdasarkan itikad baik dari para pihak yang terlibat disebut proses non litigasi sedangkan penyelesaian konflik yang diselesaikan melalui jalur hukum disebut dengan proses litigasi. ${ }^{11}$ Penyelesaian konflik di luar pengadilan merupakan upaya tawar-menawar untuk memperoleh jalan keluar yang saling menguntungkan, kehadiran mediator bersifat netral bukan untuk memutuskan sengketa namun para pihak yang terlibat memutuskan jalan keluar yang disepakati bersama-sama.

Penyelesaian konflik dengan cara alternatif yaitu penyelesaian di luar peradilan biasanya dilandasi dengan norma-norma yang berlaku di suatu masyarakat. Nilai-nilai resolusi konflik pasti terdapat pada kearifan lokal atau disebut juga dengan local wisdom pada masyarakat. Kearifan lokal dimaknai sebagai usaha manusia dengan menggunakan akal budinya untuk bertindak dan bersikap terhadap sesuatu, objek atau peristiwa yang terjadi dalam ruang tertentu. ${ }^{12}$

Setiap daerah memiliki kearifan lokal dalam menyelesaikan konflik, dan masing-masing daerah memiliki cara tersendiri. Dalam masyarakat Kerinci, resolusi konflik disebut mendawah. Resolusi konflik pada masingmasing daerah memiliki relevansi dengan kehidupan masyarakatnya, dengan demikian perselisihan yang terjadi bisa diselesaikan dengan kearifan lokal masyarakat setempat. Resolusi konflik tersebut diharapkan

${ }^{10}$ Christopher E. Miller, A Glossary of Terms and Concepts in Peace and Conflict Studies, Geneva: University Of Peace, 2005.

${ }^{11}$ Manuasa Saragi, Litigasi Dan Non Litigasi Untuk Penyelesaian Sengketa Bisnis Dalam Rangka Pengembangan Investasi Di Indonesia, E-Journal Graduate Unpar Part B : Legal Science Volume. 1, Nomor. 2, (2014).

${ }^{12}$ Lihat Nurma Ali Ridwan, “Landasan Keilmuan Kearifan Lokal” Jurnal Ibda', Volume. 5, Nomor . 1, (2007), h. 27-38 
bisa menciptakan kedamaian. Salah satu cara untuk menanamkan nilainilai lokal adalah dengan pendidikan.

\section{Resolusi Konflik Pada Masyarakat Suku Sasak}

Suku Sasak adalah suku bangsa yang mendiami pulau Lombok dan menggunakan bahasa Sasak. ${ }^{13}$ Kata Sasak berasal dari kata sak sak, artinya yang satu atau yang esa. ${ }^{14}$ Adapun menurut Tim Penyusun Kamus Pusat Pembinaan dan Pengembangan Bahasa, Sasak diartikan sebagai buluh bambu atau kayu yang dirakit menjadi satu. Sedangkan dalam Kitab Negarakertagama yakni Decawanana, Sasak dan Lombok dijelaskan dengan sebutan Lombok Mirah bagi Lombok Barat dan Sasak Adi untuk menyebut Lombok Timur. ${ }^{15}$ Bahasa Sasak dilihat dari tingkatannya sangat dekat dengan Bahasa Jawa, dan dilihat dari aksaranya sangat dekat dengan Bahasa Bali, dan juga sangat dekat dengan suku Samawa, yang notabene memiliki Bahasa yang serumpun dengan Sulawesi Tenggara yang berbahasa Tolaki. ${ }^{16}$

Sejarah orang Sasak tidak terlepas dari kolonialisme, serta pengaruh kuat dari kerajaan-kerajaan yang pernah terlibat didalamnya, seperti Majapahit, Makassar/Gowa, Karangasem, Belanda dan Jepang. Bahkan pada era awal pemerintahan pasca Indonesia merdeka, masyarakat Lombok dipimpin oleh tokoh-tokoh pemerintahan dari tanah Jawa hingga akhirnya, H.L. Serinata tercatat sebagai orang Sasak pertama yang menjadi Gubernur Nusa Tenggara Barat, pada tahun 2003. ${ }^{17}$ Secara adat dan tradisi, Interaksi antara orang Sasak dengan orang non Sasak telah membentuk identitas orang Sasak yang khas sebagaimana yang terlihat saat ini.

Suprapto dalam penelitiannya yang berjudul Revitalisasi Nilai-Nilai Kearifan Lokal Bagi Upaya Resolusi Konflik mencatat sejumlah nilai lokal

${ }^{13}$ Sudirman, Gumi Sasak dalam Sejarah, Yayasan Budaya Sasak Lestari, Lombok Timur, 2007.

${ }^{14}$ Wawancara dengan informan pertama Dr. Ali Jadid (akademisi dan pemerhati budaya Sasak) pada hari senin, tanggal 14 Desember 2020 pada pukul 09.00 Wita di Mataram

${ }_{15}$ Lalu Muhammad Ariadi, , Islam Sasak: Sebuah Manifestasi Fikih-Budaya, Jurnal Schemata, Volume 6, Nomor 2, (Desember 2017).

${ }^{16}$ Ibid, h. 156

17 Dedy Wahyudin, Identitas Orang Sasak: Studi Epistemologis Terhadap Mekanisme Produksi Pengetahuan Masyarakat Suku Sasak, Jurnal Penelitian Keislaman, Volume.14 Nomor.1 (2018): 51-62 
yang dapat menjadi modal mengbangkan berbagai upaya untuk mengelola konflik dan membangun harmoni masyarakat. Nilai-nilai kearifan lokal masyarakat sasak tersebut dapat dilacak dari naskah kuno Kotaragama, sesengak, perteke, atau lelakaq.

Tabel

Kearifan Lokal Pada Masyarakat Sasak ${ }^{18}$

\begin{tabular}{|c|c|c|c|}
\hline Prinsip & Sumber & Ungkapan & Makna \\
\hline \multirow{2}{*}{$\begin{array}{l}\text { Kejujuran } \\
\text { dan } \\
\text { kesetiaan } \\
\text { memegang } \\
\text { janji }\end{array}$} & $\begin{array}{l}\text { Naskah Kuno } \\
\text { Kotaragama }\end{array}$ & $\begin{array}{l}\text { Danta, Danti, Kusuma } \\
\text { Warsa. }\end{array}$ & $\begin{array}{l}\text { Kata dan janji wajib } \\
\text { dipegang } \\
\text { dipertahankan } \\
\text { dengan kukuh. }\end{array}$ \\
\hline & Sesengak & $\begin{array}{l}\text { Sampi betali isik pepit, } \\
\text { manuse betali isik raos. }\end{array}$ & $\begin{array}{l}\text { Manusia diikat } \\
\text { dengan kata- } \\
\text { katanya. }\end{array}$ \\
\hline \multirow[t]{4}{*}{$\begin{array}{l}\text { Menegakkan } \\
\text { /mensucikan } \\
\text { ajaran agama }\end{array}$} & \multirow[t]{4}{*}{ Perteke } & Agama betakaq adat. & $\begin{array}{l}\text { Adat menegakkan } \\
\text { dan mensucikan } \\
\text { agama. }\end{array}$ \\
\hline & & $\begin{array}{l}\text { Ndaq ta ngaken baraq } \\
\text { api. }\end{array}$ & $\begin{array}{l}\text { Larangan memakan } \\
\text { riba. }\end{array}$ \\
\hline & & $\begin{array}{l}\text { Pacu - pacu punik } \\
\text { akherat. }\end{array}$ & $\begin{array}{l}\text { Bersungguh-sungguh } \\
\text { berbuat kebajikan }\end{array}$ \\
\hline & & Rurung bender turna gantar. & $\begin{array}{l}\text { Sejahtera dan } \\
\text { tenteram jika } \\
\text { menegakkan ajaran } \\
\text { agama. }\end{array}$ \\
\hline $\begin{array}{l}\text { Persamaan } \\
\text { dan } \\
\text { kebersamaa } \\
\text { n hak }\end{array}$ & Sesengak & $\begin{array}{l}\text { Pusaka tolang daeng papuk } \\
\text { balok. } \\
\text { Dowe tengaq, Dowe } \\
\text { sopoq. } \\
\text { Nemu syarat kepeng. Dowen } \\
\text { neneq. } \\
\text { Dowen pelungguh saq }\end{array}$ & \\
\hline
\end{tabular}

${ }^{18}$.L. Syapruddin, "Nilai-nilai Kearifan Lokal yang Berlaku pada Masyarakat Sasak sebagai Pola Budaya," makalah disampaikan pada Seminar Budaya di Taman Budaya Mataram, Lihat. Suprapto, Revitalisasi Nilai-Nilai Kearifan Lokal Bagi Upaya Resolusi Konflik, Walisongo, Volume 21, Nomor 1, (Mei 2013). 


\begin{tabular}{|c|c|c|c|}
\hline & & leq tiang. & \\
\hline $\begin{array}{l}\text { Kemanusiaa } \\
\mathrm{n}\end{array}$ & Lelakaq & $\begin{array}{l}\text { Anak kaoq mondong } \\
\text { jagung, sai tao jari agung. } \\
\text { Ulah mandi isiq bisana. }\end{array}$ & \\
\hline $\begin{array}{l}\text { Pemelihara } \\
\text { an } \\
\text { lingkungan }\end{array}$ & $\begin{array}{l}\text { Ungkapan } \\
\text { Lokal }\end{array}$ & $\begin{array}{l}\text { Kurenan, gubuk, lambah, } \\
\text { penyengker, nambarayang, } \\
\text { cero, kuninga, penyaweq, } \\
\text { uriga, maliq. }\end{array}$ & \\
\hline $\begin{array}{l}\text { Perekono } \\
\text { mi dan } \\
\text { etos kerja }\end{array}$ & $\begin{array}{l}\text { Ungkapa } \\
\text { n Lokal } \\
\text { Dan } \\
\text { Sesengak }\end{array}$ & $\begin{array}{l}\text { Keduk lindung bani raok; } \\
\text { Mesang ime naen ta bawaq } \\
\text { lanjaq batur Nyuit isiq jaum; } \\
\text { Tiwas karang jari apuh; } \\
\text { Manah tan keneng obah; } \\
\text { Kendeq nenggala leq atas } \\
\text { bonggkor batur; Soroq } \\
\text { dampuk bosang } \\
\text { boros }\end{array}$ & $\begin{array}{l}\text { perlu pengorbanan } \\
\text { demi cita-cita. }\end{array}$ \\
\hline $\begin{array}{l}\text { Penyelesai } \\
\text { an konflik }\end{array}$ & Sesengak & $\begin{array}{l}\text { Empaq bau, aiq meneng, } \\
\text { tunjung tilah; } \\
\text { Adiq ta tao jauq aiq; Sifat } \\
\text { anaq empaq, tao pesopoq } \\
\text { diriq; Sikut tanggkong leq } \\
\text { awak mesaq }\end{array}$ & $\begin{array}{l}\text { Kepuasan tidak ada } \\
\text { merasa ditekan, } \\
\text { semua merasa me- } \\
\text { nang. } \\
\text { Harus mampu } \\
\text { menjadi pen- } \\
\text { dingin/penyejuk. } \\
\text { Nasihat } \\
\text { menghindari } \\
\text { sengketa. } \\
\text { Tingkah laku diukur } \\
\text { pada diri sendiri. }\end{array}$ \\
\hline
\end{tabular}

\section{Resolusi Konflik Pada Masyarakat Suku Sasak Lombok Barat}

Kabupaten Lombok Barat adalah salah satu dari tiga Kabupaten di Pulau Lombok, berdasarkan Undang-undang No. 69 Tahun 1958 tentang Pembentukan Daerah-daerah Tingkat I Bali, Nusa Tenggara 
Barat dan Nusa Tenggara Timur, ${ }^{19}$ yang kemudian melahirkan Kota Mataram dan Kabupaten Lombok Utara. Kabupaten Lombok Barat terdiri dari 10 Kecamatan, 3 Kelurahan, dan 119 Desa. $^{20}$

Lombok Barat memiliki karakteristik khas yang berasal dari kehidupan masyarakatnya sehari-hari, baik dari segi agama, kebudayaan dan juga adat-istiadatnya, khususnya nilai-nilai resolusi konflik yang tersirat dalam semboyan masyarakat kabupaten Lombok Barat patut patuh patju, dengan menggunakan penelitian Kualitatif Fenomenologi, yakni berhubungan dengan interpretasi terhadap realitas dan atau mencari jawaban tentang makna dari suatu fenomena. $^{21}$

Masyarakat Lombok Barat dalam pembangunannya mengusung semboyan yang menginterpretasikan kesimpulan dari segala kekhasannya yang disebut Patuh, Patut, Patju yang tertuang dalam Peraturan Daerah Lombok Barat dengan Perda No.3 Tahun 1970 yang disetujui dengan Keputusan Menteri Dalam Negeri No. Pemda 10/36/2.247 tanggal 16 Desember 1972. Adapun falsafah pembangunan tersebut jika dilihat dari etimologis bahasa Sasak yaitu pertama, Patut artinya adalah baik, terpuji, dan tidak berlebihan. Kedua, Patuh artinya rukun, taat, damai, toleransi saling menghargai. Ketiga, Patju artinya rajin, giat, tidak mengenal putus asa.

Suku Sasak meyakini bahwa agama dan adat sama-sama bisa berjalan beriringan tanpa saling menafikan. Lebih dari itu, pranata adat dengan segala simbol yang dimiliki merupakan cerminan bentuk

${ }^{19}$ Lembaran Negara Tahun 1958 No. 122, Tambahan Lembaran Negara No. 1655

${ }^{20}$ Badan Pusat Statistik Kabupaten Lombok Barat, Tahun 2020.

${ }^{21}$ Hasbiansyah , Pendekatan Fenomenologi: Penelitian dalam Ilmu Sosial dan Komunikasi. Mediator Volume 9 Nomor 1. (Juni 2008). 
pemahaman dari ajaran agama Islam sebagai agaman yang dianut mayoritas masyarakat Lombok. Sistem nilai dalam budaya Sasak terdiri dari tiga lapis: 1) nilai-nilai dasar filosofis. Di mana pada lapis pertama inilah nilai tindih ada, sebagai sumber memotivasi orang Sasak untuk menjadi manusia yang patut (benar), patuh (taat), patju (rajin), solah (baik) dan soleh (saleh, damai). 2) penyangga moral. Pada lapis kedua, ini terdapat nilai maliq (larangan) dan merang (semangat berbuat baik dan positif).

Adapun lapis 3) simbol aplikatif dari dua lapis sebelumnya, yakni implementasi kolektif dalam membangun kebaikan secara bersamasama seumpama prosesi sangkep (musyawarah). ${ }^{22}$ Merujuk kepada pemaparan tersebut diatas maka jika dicermati lebih jauh, semboyan patut, patuh, patju ini tidak hanya berimplikasi baik bagi pembangunan, namun dapat pula ditarik pada nilai-nilai resolusi konflik.

\section{Implentasi Nilai Patut}

Kata patut yang berarti juga cocok, serasi, harmoni, baik, dan tidak berlebihan serta merupakan nilai instrumental yang berkaitan dengan norma kebaikan ${ }^{23}$ jika ditarik dalam nilai-nilai Islam maka merujuk pada sikap akhlakul karimah sebagaimana hadis Nabi :

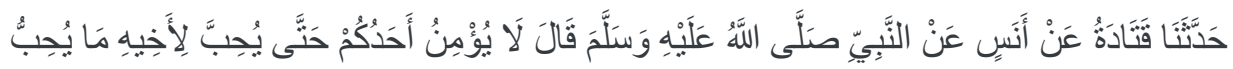

"Tidaklah seorang diantara kalian dikatakan beriman hingga ia mencinta untuk saudaranya apa-apa yang ia sukai untuk dirinya sendiri." (HR. Bukhari)

${ }^{22}$ Sabirin. Konfigurasi Pemikiran Islam Tuan Guru: Respon Pemikiran Tuan Guru Terhadap Penetrasi Ajaran Wahabi pada Etnik Sasak di Pulau Lombok 1993-2007. Tesis. Program Pascasarjana UI, 2008, h. 25-26.

${ }^{23}$ Wawancara dengan informan kedua Dr. Saharudin (akademisi dan alumnus S3 Bahasa UGM) pada hari selasa 15 Desember 2020, pukul 08.00 Wita di Mataram. 
Melakukan sesuatu atau bersikap kepada orang lain hanya dengan sikap yang kita kehendaki atau sukai orang lain lakukan pada diri kita atau sikap yang kita anggap sebagai sesuatu yang patut akan sangat diperlukan Ketika seseorang berada pada situasi konflik, baik dengan orang lain atau kelompok lain. Mengapa demikian?, karena adanya kesadaran yang tinggi akan norma agama tentang kepatutan dalam sikap hidup yang akan menghantarkan pada keterbukaan fikiran dan kemauan dalam menjalani proses penyelesaian konflik yang sedang berlangsung.

\section{Implentasi Nilai Patuh}

Kata patuh yang berarti juga taat, patuh, damai, akur, cinta kasih serta merupakan nilai instrumental yang berkaitan dengan norma sosial $^{24}$ jika ditarik dalam nilai-nilai Islam maka merujuk pada sikap akhlakul karimah sebagaimana hadis nabi :

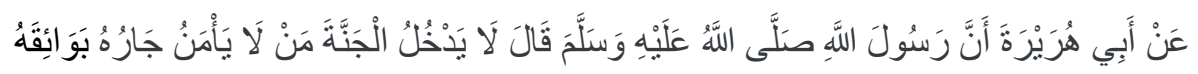

"Tidak akan masuk Surga orang yang tetangganya tidak aman dari gangguannya."

(HR. Muslim)

Umumnya dalam tiap usaha atau proses penyelesaian suatu konflik dimunculkan pihak ketiga sebagai penengah, yang biasanya dipilih dari tokoh agama, atau adat, atau orang yang dituakan ditengah keluarga jika. Hal demikian dilakukan mengingat kuatnya system anutan pada budaya masyarakat Lombok atau suku Sasak, yang menghantarkan kepada kepatuhan atas apa yang disampaikan oleh mereka yang dipanuti, sebagai bentuk rasa hormat dan segan yang diyakini akan membawa pada keberkahan hidup. Hal demikian tentu sangat penting

${ }^{24}$ Wawancara dengan informan kedua Dr. Saharudin (akademisi dan alumnus S3 Bahasa UGM) pada hari selasa 15 Desember 2020, pukul 08.15 Wita di Mataram. 
dan dapat menjadi peluang besar bagi terselesaikannya suatu konflik, dimana petuah bijak dari sang tokoh diharapkan akan menjadi penuntun bagi terciptanya perdamaian antara kedua belah pihak.

\section{Implentasi Nilai Patju}

Kata patju yang berarti tekun, bersungguh-sungguh, dan pantang menyerah, merupakan nilai instrumental yg berkaitan dengan norma kebenaran (sesuai fungsi dan peran) ${ }^{25}$ sehingga jika ditarik dalam nilainilai Islam maka merujuk pada sikap akhlakul karimah sebagaimana hadis nabi:

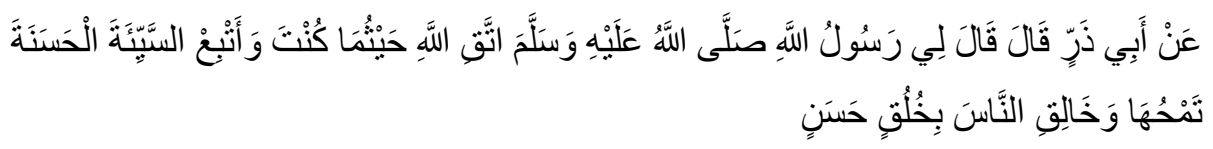

"Dari Abu Dzar radhiallahu anhu, ia berkata, Rasulullah shallallahu alaihiwassallam pernah bersabda kepadaku, "Bertakwalah kamu kepada Allah dimana saja kamu berada dan ikutilah setiap keburukan dengan kebaikan yang dapat menghapuskannya, serta pergaulilah manusia dengan akhlak yang baik." (HR. At Tirmidzi)

Hadis tersebut menekankan agar manusia umumnya dan ummat Islam khususnya mengedepankan sifat penerimaan atau ikhlas dalam menerima dan menyadari kesalahannya dengan cara tidak mengulangi dan mengiuti keburukan yang telah dilakukan dengan perbuatan baik yang diharapkan dapat menghapus sisa-sisa permasalahan yang ada. Hal demikian mengingat umumnya konflik meskipun telah diinisiasi perdamaiannya tidak serta merta melenyapkan konflik atau permasalahan tersebut, tetap masih memiliki peluang menyisakan rasa marah, kecewa, dendam bahkan keterpaksaan.

${ }^{25}$ Wawancara dengan informan kedua Dr. Saharudin (akademisi dan alumnus S3 Bahasa UGM) pada hari selasa 15 Desember 2020, pukul 08.20 Wita di Mataram. 
Dalam kata patju ditekankan makna bersungguh-sungguh dalam melakukan sesuatu, sehingga Ketika berkaitan dengan masalah resolusi konflik maka diharapkan para pelaku konflik yang terlibat dengan sungguh-sunguh menanamkan dalam fikiran dan nalarnya untuk berteguh diri melepaskan segala bentuk perasaan tidak rela dan fikiran buruk lainnya, sehingga perdamaian akan menjadi tidak mustahil untuk diciptakan. Optimisme akan lahirnya perdamaian pasca konflik diperkuat dengan mengingat masyarakat Sasak dalam tradisi kearifannya mengenal istilah krame (norma) dan awig-awig (aturan) yang digunakan oleh masyarakat Sasak sebagai mengatur kehidupan bersama dalam harmoni. ${ }^{26}$

\section{Kesimpulan.}

Diharapkan kekayaan akan kearifan lokal masyarakat suku Sasak yang tercermin dalam bahasa, ritual-ritual, tradisi, kisahkisah rakyat yang syarat dengan nilai-nilai kebajikan dan kaya dengan nilai-nilai ajaran agama dapat menjadi kartu pamungkas dalam memperbaiki watak serta sikap hidup yang dipilih, sehingga ketika suatu permasalahan muncul baik berupa persoalan pribadi maupun yang berkenaan dengan konflik antar kelompok akan dengan mudah memiliki ruang yang terbuka dalam menyelesaikannya.

Akhirnya, kajian pada tulisan ini menekankan bahwa kearifan lokal masyarakat Sasak yang tertuang dalam semboyan hidup dan diabadikan sebagai motto daerah kabupaten Lombok Barat

${ }^{26}$ Sabirin. Konfigurasi Pemikiran Islam Tuan Guru: Respon Pemikiran Tuan Guru Terhadap Penetrasi Ajaran Wahabi pada Etnik Sasak di Pulau Lombok 1993-2007. Tesis. Program Pascasarjana UI, 2008, h. 33-34. 
yakni patut, patuh, patju bukan sebagai motto pembangunan saja namun sebagai seperangkat nilai dalam penanganan konflik di tengah-tengah masyarakat, baik konflik laten maupun manifest yang berkaitan dengan kehidupan sehari-hari.

Konflik tidak hanya dapat terjadi pada person-person pada masyarakat namun dapat pula terjadi dengan lembaga pendidikan, organisasi maupun kelompok kecil dengan tidak selalu memandang kemunculan dampak negatif, namun konflik dapat berdampak positif bagi kelangsungan kinerja Lembaga. Konflik akan produktif dengan syarat resolusi konflik dilakukan secara keterbukaan dengan frekusensi lebih baik sebagai langkah awal pengelolaan konflik yang benar, dan dijadikan peluang untuk melakukan sebuah perubahan.

Penulis berharap penanganan konflik sebagai sebuah keharusan akan menjadi lebih mungkin dengan mengedepankan tradisi yang telah mengakar ditengah masyarakat, dan pemahaman yang baik bahwa konflik merupakan sebuah wahana dalam mewarnai kehidupan agar lebih bermakna. 


\section{Daftar Pustaka}

Agus Dedi Putrawan, Sekolah Perjumpaan Sebagai Gerakan Dakwah Berbasis Komunitas, Jurnal Lentera, Volume 02, Nomor. 02, (2018),

L. Syapruddin, "Nilai-nilai Kearifan Lokal yang Berlaku pada Masyarakat Sasak sebagai Pola Budaya," makalah disampaikan pada Seminar Budaya di Taman Budaya Mataram.

Badan Pusat Statistik Kabupaten Lombok Barat, Tahun 2020.

Christopher E. Miller, A Glossary of Terms and Concepts in Peace and Conflict Studies, Geneva: University Of Peace, 2005.

Dedy Wahyudin, Identitas Orang Sasak: Studi Epistemologis Terhadap Mekanisme Produksi Pengetahuan Masyarakat Suku Sasak, Jurnal Penelitian Keislaman, Volume. 14 Nomor.1 (2018).

Fahrurrazi, "Konflik Agama dan Etika Dialog: Membaca Dialog Kemanusiaan dalam Bingkai Sosiologi Komunikasi," Jurnal Tasamuh 12, Nomor. 1 (Desember 2014).

Hasbiansyah, Pendekatan Fenomenologi: Penelitian dalam Ilmu Sosial dan Komunikasi. Mediator Volume 9 Nomor 1. (Juni 2008).

Lalu Muhammad Ariadi, , Islam Sasak: Sebuah Manifestasi Fikih-Budaya, Jurnal Schemata ,Volume 6, Nomor 2, (Desember 2017).

Lembaran Negara Tahun 1958 No. 122, Tambahan Lembaran Negara No. 1655

Lewis Coser, the Function Of Social Conflict, New York, Routledge, 1956. Manuasa Saragi, Litigasi Dan Non Litigasi Untuk Penyelesaian Sengketa Bisnis Dalam Rangka Pengembangan Investasi Di Indonesia, EJournal Graduate Unpar Part B : Legal Science Volume. 1, Nomor. 2, (2014).

Newstrom, J. and Davis, K. Human Behavior at Work. Organization Behavior 8th Edition. Singapore: Mc. Graw-Hill. International 1993.

Novri Susan dalam buku Sosiologi Konflik: Teori-teori dan Analisis, Jakarta: Kencana Prenada, 2009.

Novri Susan, Sosiologi Konflik dan Isu-Isu Konflik Kontemporer, Jakarta: Kencana Prenada, 2009.

Nurma Ali Ridwan, " Landasan Keilmuan Kearifan Lokal” Jurnal Ibda”, Volume. 5, Nomor . 1, (2007).

Prof. Dr. Gunaryo "Pendidikan Islam dan Resolusi Konflik”. 28 Oktober Via Zoom Pada Perkuliahan Pasca Sarjana S3 UIN Mataram .

Pupun Sofiyati, dkk, Konflik dan stress; pengembangan dan perilaku organisasi. Malang: Universitas Brawijaya. 2011. 
R. Wayne Pace dan Don F. Faules, Komunikasi Organisasi : Strategi Meningkatkan Kinerja Perusahaan, Editor Deddy Mulyana, Bandung: Remaja Rosda Karya, 2000,.

Sabirin. Konfigurasi Pemikiran Islam Tuan Guru: Respon Pemikiran Tuan Guru Terhadap Penetrasi Ajaran Wahabi pada Etnik Sasak di Pulau Lombok 1993-2007. Tesis. Program Pascasarjana UI, 2008.

Sudirman, Gumi Sasak dalam Sejarah, Yayasan Budaya Sasak Lestari, Lombok Timur, 2007.

Suprapto, Revitalisasi Nilai-Nilai Kearifan Lokal Bagi Upaya Resolusi Konflik, Walisongo, Volume 21, Nomor 1, (Mei 2013).

Wawancara dengan informan kedua Dr. Saharudin (akademisi dan alumnus S3 Bahasa UGM) pada hari selasa 15 Desember 2020, pukul 08.00 Wita di Mataram.

Wirawan. Konflik dan manajemen konflik. Jakarta: Salemba Humanika, 2010.

Sabirin. Konfigurasi Pemikiran Islam Tuan Guru: Respon Pemikiran Tuan Guru Terhadap Penetrasi Ajaran Wahabi pada Etnik Sasak di Pulau Lombok 1993-2007. Tesis. Program Pascasarjana UI, 2008. 